\title{
Improving medical communication: Skills for a complex (and multilingual) clinical world
}

\author{
Peter G Brindley MD FRCPC FRCP Edin ${ }^{1}$, Katherine E Smith MD², \\ Pierre Cardinal MD FRCPC ${ }^{3}$, Francois LeBlanc MD FRCPC ${ }^{4}$
}

\begin{abstract}
$\mathrm{T}$ he ability to communicate can be one of the clinician's greatest assets... or greatest liabilities. Suboptimal communication appears to be the largest source of preventable medical error during acute clinical care (1-4) and 'the most important but least accomplished aspect of quality care' (5-7). Verbal communication (between physicians and patients, families and surrogate decision makers) is also the means by which we coordinate (or fragment) ongoing care, bolster (or impair) teamwork and generate (or erode) trust (1-7). Therefore, being an expert clinician means becoming an expert communicator (2-11). Our 'verbal dexterity' should match our procedural dexterity and factual knowhow (4).

Clinical medicine previously focused on scientific discovery and technological advancement. However, medicine is also a complex social system (1-8). Therefore, we also need to make a 'science of reducing complexity', a 'science of managing uncertainty' and a 'science of working in teams' (12). If we define communication as 'sharing, uniting, or making understanding common' (2-4), then this skill is essential to create a more reliable and patient-focused system $(3,13)$. The present review outlines the importance of medical communication. It also offers practical strategies for practitioners eager to help patients who are unable to communicate fully due to knowledge, illness or language barriers.
\end{abstract}

\section{COMMUNICATION MATTERS}

Communication skills are not always innate, cannot always be intuited and may not be ameliorated by more experience (2-4,8-14). Fortunately, communication training for medical practitioners has been associated with increased confidence, and improved patient satisfaction, anxiety, depression and post-traumatic stress disorder $(2,15$ 17). Both what we say and how it is communicated can be a placebo (ie, good communication can reduce pain and anxiety) or a nocebo (ie, bad communication can increase pain and anxiety) (2). Good communication may also decrease litigation and improve hospital reputation $(2,11)$. In short, communication is everybody's business (3). It should be taught to trainees and expected from seasoned practitioners.

The CanMEDS framework (8), from the Royal College of Physicians and Surgeons of Canada, states that practitioners become expert communicators and advocators - not simply technicians or scientists. Similarly, the Society of Critical Care Medicine endorses more communication training, more communication research, and expects communication to be proactive, structured and family centred (13). We have accepted that communication matters - whether with vulnerable patients, anxious families, high-stakes resuscitation teams or multidisciplinary care groups. Fortunately, diverse insights and resources translate readily to our clinical reality.

\section{PRACTICAL STRATEGIES FROM OUTSIDE OF CLINICAL MEDICINE}

Work from the social sciences emphasizes that good communication is more that just the words that are said. Paraverbal communication refers to how words are said (pitch, volume, pacing and emphasis)
(2-4). Nonverbal communication also requires that clinicians display suitable eye contact, appropriate body language, attend to emotions, show active listening and use reflective silence (2-4). Moreover, we really cannot NOT communicate, because failing to make the effort likely sends its own message. This helps to explain why patients and families are frequently dissatisfied, and regularly value clinicians' communication skills as equal or greater than clinical skills $(5,7,18)$.

Although Situation/Background/Assessment and Recommendation (SBAR) originated with the military, it offers acute medicine a basic structure for interprofessional communication, particularly during complexity or when individuals are strangers (2-4). SBAR can also add structure to nonacute discussions between health care providers and recipients. Medical 'closed-loop communication', which originated with aviation, demands feedback to confirm that instructions were heard and understood. Similarly, this can be applied to the family conference by asking patients, families or surrogate decision makers to 'close the loop' and repeat back key points (2-4). Clinical medicine has also developed its own tools. The following is far from comprehensive and readers are encouraged to explore further.

\section{PRACTICAL STRATEGIES FROM INSIDE CLINICAL MEDICINE}

The Calgary-Cambridge guide divides the medical interview into: initiate the session; gather information; provide structure; build a relationship; explain and plan; and close the session $(2,6)$. There is also the GREAT technique (Greetings/Goals; Rapport, Evaluation/ Expectation/Examination/Explanation; Ask/Answer/Acknowledge; Tacit agreement/Thanks), and the LAURS technique (Listening; Acceptance; Utilization [of appropriate words]; Reframing; and Suggestion). The VALUE framework (Value family statements; Acknowledge emotions; Listen; Understand the patient as a person; Elicit questions) can facilitate shared decision-making, and the SPIKES technique (Settings; Patient perception; Invitation to share; Knowledge transmission; Emotions and Empathy; Summarize and Strategize) is recommended when delivering bad news (2,19-21).

Black et al (21) promoted a communication bundle (as part of a multifaceted quality-improvement process). Six activities are expected within day one: identification of the surrogate-decision maker; code status; advance directive; pain; dyspnea; and distribution of a brochure. Four additional goals are to be met by the end of day three: family meeting; discuss prognosis; assess patient-specific goals; and offer spiritual care. Tools and bundles provide structure and reliability to complex communication. They also promote communication as more than just facts transmitted from doctor to patient. The patient is validated as someone with beliefs and values, and as part of a larger 'life-support system' that includes family, friends and community $(13,18,20,21)$.

COMMUNICATION: MORE THAN WORDS CAN SAY

The expression "people do not care how much you know unless they know how much you care" has been attributed to Theodore Roosevelt. This should inform clinicians regardless of whether delivering news,

\footnotetext{
${ }^{1}$ Division of Critical Care Medicine; ${ }^{2}$ Department of Emergency Medicine, University of Alberta, Edmonton, Alberta; ${ }^{3}$ Department of Critical

Care, University of Ottawa, Ottawa, Ontario; ${ }^{4}$ Département d'anesthésiologie, Division de Soins Intensifs, Université Laval, Laval, Quebec

Correspondence: Dr Peter G Brindley, 3c1.04 University of Alberta Hospital, Edmonton, Alberta T6G $2 B 7$.

Telephone 780-407-8822, fax 780-407-1224, e-mail peter.brindley@albertahealthservices.ca
} 
providing comfort, lessening hostility, combating disbelief or mitigating denial $(2,3,6-7)$. Particularly when communicating bad news, we should remember that, while routine for us, these are conversations that families are unlikely to forget $(2,3,9-10)$. Combined with 'active listening', the effort put into communication becomes a key way to demonstrate nonabandonment (2,3). Investing the time to establish initial 'rapport' (usually defined as 'common perspective'; 'being in sync' or 'on the same page') can facilitate all future interactions $(2,11)$ and reinforce the patient's psychological reserves $(2,3)$.

Insights apply to those who cannot communicate (eg, endotracheal tube, tracheostomy, tongue resection, etc), just as with those who do not talk because of fear or confusion. For patients already burdened with illness, not being able to verbalize and not being understood can hasten a downward spiral into disengagement $(2,3)$. Moreover, even when physicians do speak, we may not speak 'the same language' as patients $(2,3,9,10)$. In addition to technical language, physicians often focus on gathering information or delivering news $(2,3,9,10)$. Patient language may be more concerned with beliefs, fears and hopes. Similarly, patient (and family) coping mechanisms may include regression, denial and aggression, whereas caregivers intellectualize to protect their emotions $(2,3,9,10)$. Communication that is sensitive, but also objective, can provide a bridge between the 'natural world' of patients and families and the 'scientific world' of caregivers $(20,21)$.

\section{LOST IN TRANSLATION}

Communication difficulty can be compounded when patients (or families) speak other languages. When we cannot communicate in a patient's native language, we probably treat them differently, even if unintentionally $(2,22-24)$. Even with sufficient time, we are less likely to discuss psychosocial issues or provide lifestyle counselling. When we cannot connect by communicating directly, we are probably less connected overall. Some humanity may be lost and patients may find it more difficult to trust $(22,23)$. Communicating with other cultures is beyond the scope of the present review, but can further exacerbate the situation, especially if there are different ideas about autonomy or disclosure.

Using translators can be fraught with potential error (2,22-24). First, using ad hoc translators, such as family members or friends, is associated with more errors than using professional translators $(2,22$ 24). Using friends or family to translate can also impact confidentiality, and increase distress and conflict $(2,22)$. However, even with professional translators, communication errors are common. For example, a small study $(n=10)$ of intensive care family meetings involving a professional interpreter found a communication alteration in more than one-half. More than three-quarters of these were deemed clinically significant (24).

The unusual hours and time pressures of acute medicine mean that translators are not always available $(2,22,23)$. For years, clinicians have used boards (containing common words or drawings). Nowadays, portable smartphone (ie, Google translate [Google, USA]) and tablet applications (ie, Vidatak ${ }^{\mathrm{TM}}$ ) can translate, and other innovative devices will, no doubt, be designed over time (eg, the 'Eye-Writer' is a clever prototype communication device for locked-in patients) (25). Many hospitals also have telephone translation services. Unfortunately, all translation strategies take more time and impair the conversational flow (2,22-24). This can mean less information is delivered, less time reserved for questions and less emotional support provided $(2,22,23)$. Accordingly, patients requiring translation may be less satisfied with their care, less informed when providing consent and may exhibit less outpatient compliance (22-24).

Translators are valuable but error prone. Reasons are diverse but include inadequate medical comprehension or the misguided desire to protect patients (ie, some translators regarding themselves as 'cultural buffers') (2,22-24). Clinicians are encouraged to conduct a pretranslation briefing and to emphasize the need for accuracy (and sensitivity)
$(2,24)$. Briefing should include the gravity of the diagnosis and the degree of certainty. It is also advisable to debrief afterward $(2,24)$. This reviews what went well, how to proceed in the future and even the translator's emotional state $(2,24)$. Additional resources, including advice, are available from the International Medical Interpreters Association, the Minnesota Department of Health, and the Health Care Interpretation Network (26-28). Simulations, whether with mock patients or actual translators, also offer an opportunity for immersion, reflection and risk-free practice. Despite the apparent simplicity of verbal simulations, they may be as realistic as the simulations that require high-technology plastic manikins. They also require minimal cost and logistics (29).

\section{MEDICAL COMMUNICATION IN CANADA}

Canada is one of the world's most multicultural nations. According to the 2011 census, $57 \%$ of Canadians use English and 21\% use French as their mother tongue (30). While approximately 20\% are allophones (and 0.5\% speak indigenous languages), 85\% possess a 'working knowledge' of English and 30\% possess a 'working knowledge' of French (30). Overall, French and English remain Canada's dominant languages (30). However, they are obviously not the number one and number two languages in all Canadian jurisdictions. Fortunately, $>98 \%$ of Canada's inhabitants can speak at least one of the two official languages. Unfortunately, $<20 \%$ speak both (30). Accordingly, Canada has been described as a country of 'two solitudes', separated by these two European founding languages (30).

Even when using translators, the ability to communicate a few phrases (and the effort demonstrated) may strengthen a therapeutic alliance. While full bilingualism requires immersion and extended practice, many of us have rudimentary language skills that can be augmented. Fortunately, many universities offer courses that can be accessed by medical faculty. Unfortunately, medical words and expressions are rarely included, and often difficult to find elsewhere. Regardless, improving how we communicate medically in a bilingual country (and a multilingual world) has the potential to bring together two other potential solitudes, namely clinicians and patients.

\section{IN CLOSING}

Communication is acute care medicine's most important nontechnical skill (1-7). It is how we exchange meaning, reduce complexity, address uncertainty, promote a shared mental model, inform, encourage, comfort and challenge $(2,3,9-11)$. Communication is central to the human experience of illness (2-4), and includes not just patient and doctor, but also the family or surrogate decision makers, and the larger medical team. Because we work in an environment under constant stress, we should not be surprised if patients (and families) doubt whether anyone will take the time to explain or to listen $(2,3,6-11)$. If we truly believe in being patient focused and family focused, we should seize all opportunities to verbalize that we care.

\section{FIVE RECOMMENDATIONS}

1. Communication should be promoted as one of our most important medical skills.

2. Proficiency in communication should not (and need not) be left to chance

3. We should know (and practise) basic communication tools.

4. We must know the basics (and hazards) of using translators.

5. Strategies exist for language-discordant patients and (again) practice is recommended.

DISCLOSURES: The author has no financial disclosures or conflicts of interest to declare. 


\section{REFERENCES}

1. Sutcliffe KM, Lewton E, Rosenthal MM. Communication failures: An insidious contributor to medical mishaps. Acad Med 2004;79:186-94.

2. Cyna AM, Andrew MI, Tan SM, Smith AF, eds. In: Handbook of Communication in Anaesthesia \& Critical Care: A Practical Guide to Exploring the Art. New York: Oxford University Press; 2011.

3. St Pierre M, Hofinger G, Buerschaper C, et al. Crisis management in acute care settings: Human factors and team psychology in a high stakes environment. New York: Springer, 2008.

4. Brindley PG, Reynolds SF. Improving verbal communication in critical care medicine. J Crit Care 2011;26:155-9.

5. Azoulay E, Chevret S, Leleu G, et al. Half the families of ICU patients experience inadequate communication with physicians. Crit Care Med 2000;8:3044-9.

6. Arnold R, Nelson J, Prendergast T, et al; for the C3 investigators. Educational Modules for the Critical Care Communication (C3) Course - A Communication Skills Training Program for Intensive Care Fellows. <www.capc.org/palliative-care.../Training/c3-moduleipal-icu.pdf $>$ (Accessed January 1, 2014).

7. Azoulay E, Sprung CL. Family-physician interactions in the intensive care unit. Crit Care Med 2004;32:2323-8.

8. The Royal College of Physicians and Surgeons of Canada. CanMEDS 2005 Framework. <www.royalcollege.ca/portal/page/ portal/rc/common/documents/canmeds/framework/the_7_canmeds_ roles_e.pdf> (Accessed January 1, 2014).

9. Tate P. The Doctor's communication Handbook, 6th edn. Milton Keynes: Radcliffe Publishing Ltd, 2009.

10. Silverman J, Kurtz S, Draper J. Skills For Communicating With Patients, 3rd edn. Milton Keynes: Radcliffe Publishing, 2013.

11. Woods D. Communication For Doctors - How to improve patient care and minimize legal risks. Milton Keynes: Radcliffe Publishing, 2004.

12. Gawande A. The Checklist. In: Gawande A, ed. The Checklist Manifesto. New York: Henry Holt and Company, 2009:32-48.

13. Davidson JE, Powers K, Hedayat KM, et al. Clinical practice guidelines for support of the family in the patient-centered intensive care unit: American College of Critical Care Medicine Task Force 2004-2005. Crit Care Med 2007;35:605-22.

14. Fallowfield L, Jenkins V, Farewell V, Saul J, Duffy A, Eves R. Efficacy of a cancer research UK communication skills training model for oncologists: A randomised controlled trial. Lancet 2002;359:650-6.

15. Lautrette A, Darmon M, Megarbane B, et al. A communication strategy and brochure for relatives of patients dying in the ICU. N Engl J Med 2007;356:469-78.

16. Curtis JR, White DB. Practical guidance for evidence-based ICU family conferences. Chest 2008;134:835-43.
17. Shaw DJ, Davidson JE, Smilde RI, Sondoozi T, Agan D. Multidisciplinary team training to enhance family communication in the ICU. Crit Care Med 2014:42:265-71.

18. Heyland DK, Rocker GM, Dodek PM, et al. Family satisfaction with care in the intensive care unit: Results of a multiple center study. Crit Care Med 2002;30:1413-8.

19. Baile WF, Buckman R, Lenzi R, Glober G, Beal EA, Kudelka AP. SPIKES - a six-step protocol for delivering bad news; application for the patient with cancer. Oncologist 2000;5:302-11.

20. Rusinova K, Simek J. Why are they all so keen on communication? Crit Care Med 2013;41:2435-6.

21. Black MD, Vigorito MC, Curtis JR, et al. A multifaceted intervention to improve compliance with process measures for ICU clinician communication with ICU patients and families. Crit Care Med 2013;41:2275-83.

22. Flores G, Laws MB, Mayo SJ, et al. Errors in medical interpretation and their potential consequences. Pediatrics 2005;111:6-15.

23. Thornton JD, Pham K, Engelberg RA, Jackson JC, Curtis JR. Families with limited English proficiency receive less information and support in interpreted intensive care unit family conferences. Crit Care Med 2009;37:109-18.

24. Pham K. Alterations during medical interpretation of ICU family conferences that interfere with or enhance communication. Chest 2008;134:109-18.

25. The eyewriter. <www.notimpossiblelabs.com> (Accessed January 1, 2014).

26. imiaweb.org International Medical Interpreters association. IMIA Guide on Working with medical interpreters. <www.imiaweb.org/ uploads/pages/380_5.pdf> (Accessed January 1, 2014).

27. Minnesota Department of Health. Minnesota Refugee Health Provider Guide 2010 - Ch 11 - Medical Interpreters. (revised). 2010. <www.health.state.mn.us/divs/idepc/refugee/guide/index. html> (Accessed January 1, 2014).

28. Healthcare Interpretation Network. <www.healthcareinterpretationnetwork.ca/eng/resources.htm>. (Accessed January 1, 2014).

29. Brindley PG. Novel technique for critical care training. Can Med Assoc Journal 2007;176:68.

30. Statistics Canada. Population by mother tongue and age groups (total), 2011 counts, for Canada, provinces and territories. <www12.statcan.gc.ca/census-recensement/2011/dp-pd/hlt-fst/lang/ Pages/highlight.cfm?TabID $=1 \&$ Lang $=E \& A s c=0 \& P R$ Code $=01 \&$ Ord erBy $=2 \&$ View $=1 \&$ tableID=401\&queryID $=1 \&$ Age = $1 \#$ TableSumma ry> (Accessed January 1, 2014). 


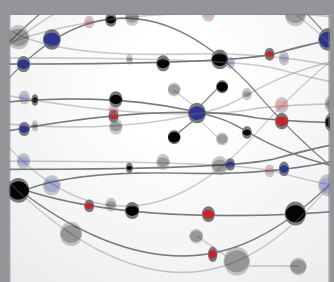

The Scientific World Journal
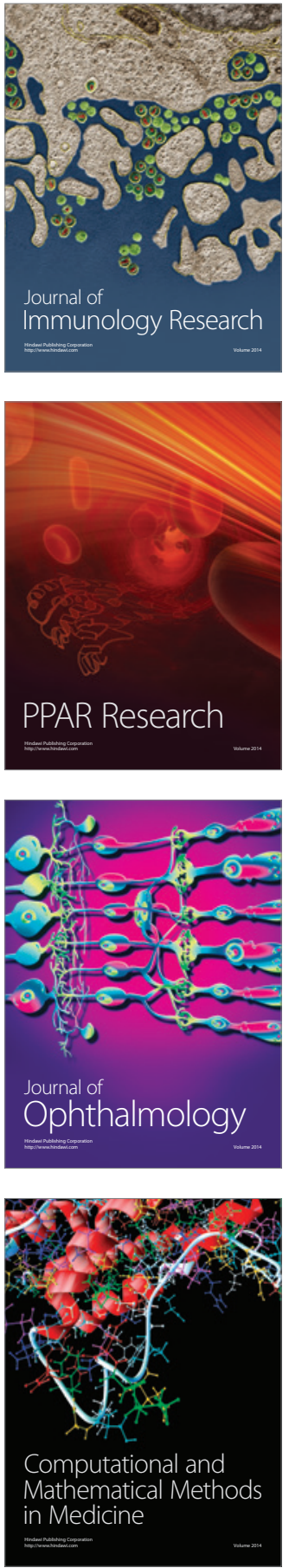

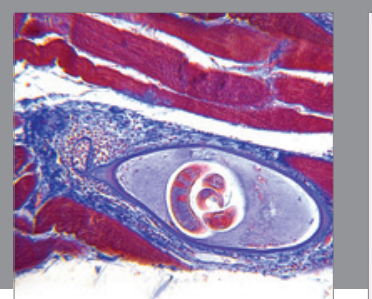

Gastroenterology Research and Practice

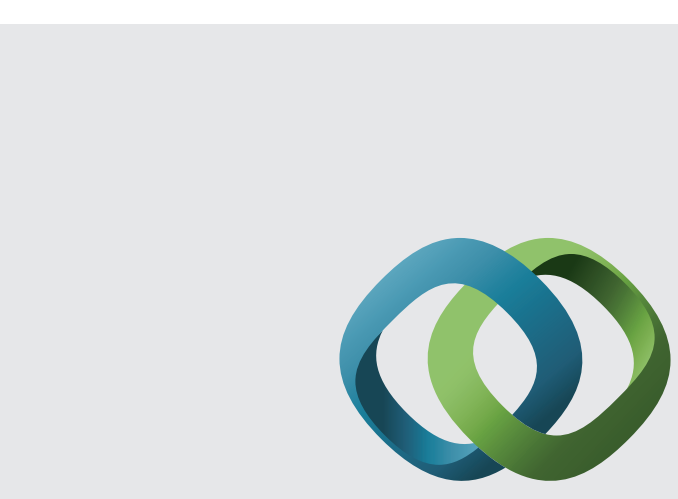

\section{Hindawi}

Submit your manuscripts at

http://www.hindawi.com
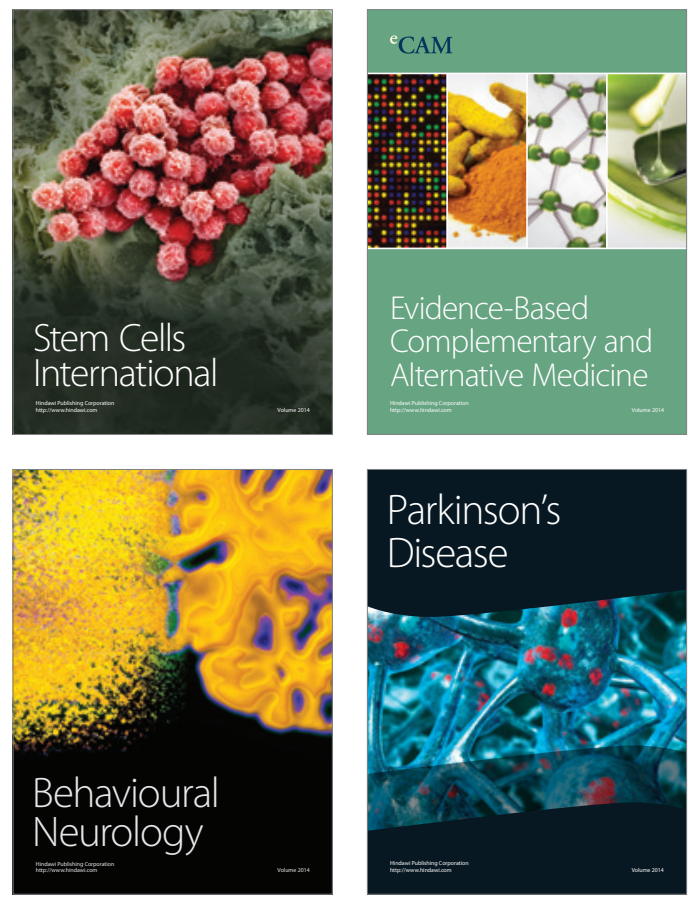
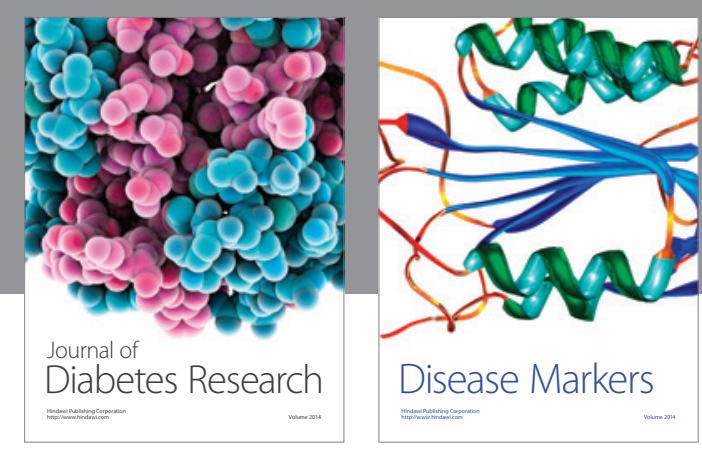

Disease Markers
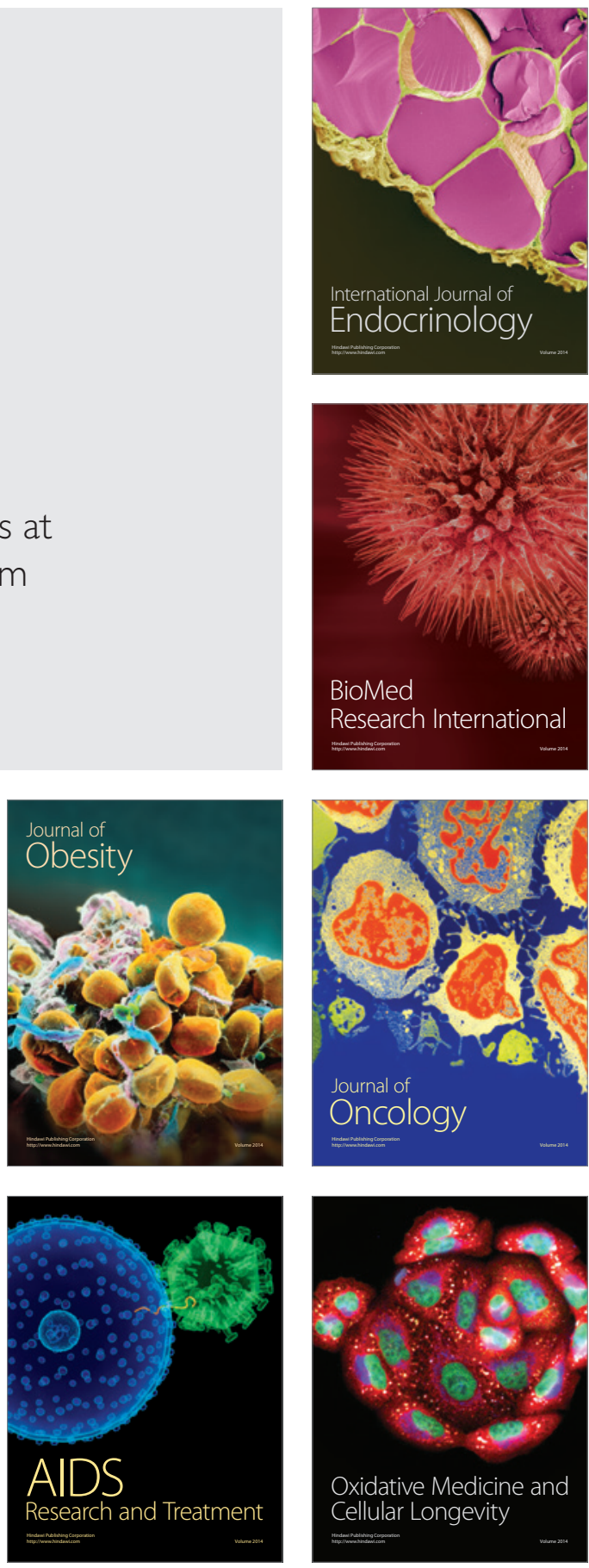